hoop, $842 \mathrm{ft}$. in diameter, and will use the new 'strong focusing' principle of accelerator design to accelerate protons to energies of $25,000 \mathrm{MeV}$. The Brookhaven research reactor, completed in 1950, operates at 30 megawatts, and is a natural uranium, graphite-moderated, air-cooled reactor. It is used for many types of experiments in nuclear research, including a large number of simultaneous experiments involving neutrons and also for the production of radioisotopes. The nuclear engineering department is continuing to contribute to the general development of a liquid-metal fuel reactor and is collaborating closely with Messrs. Babcock and Wilcox, who are responsible for the engineering aspects of the design, fabrication and operation of a liquid-fuel reactor experiment for the U.S. Atomic Energy Commission. The experiment is based on research work done at the Laboratory on the concept of a reactor using uranium fuel dissolved in molten bismuth.

Brookhaven was the first institution in the United States to establish a hospital devoted primarily to research in the use of atomic energy for the diagnosis and treatment of disease. The hospital has 115 beds and treats 'terminal cases', that is, persons suffering from an incurable disease, usually some form of cancer. A new Medical Research Centre is being built which will house a forty-eight-bed research hospital, an industrial medical branch and research departments in medical physics, pathology, microbiology, biochemistry and physiology. The Centre will have the first nuclear reactor designed specifically for medical research and therapy and will be capable of producing a beam of neutrons about fifty times as powerful as the beam from Brookhaven's present general research reactor.

\section{PASTEUR INSTITUTE OF SOUTHERN INDIA}

$\mathrm{T}$

HE brilliant research of Louis Pasteur in the

1880-90 decade not only established bacteriology as a science but also revolutionized the practice of medicine by the introduction of therapeutically and often dramatically effective sera and vaccines. Public recognition of the value to humanity of this new science led to the establishment of, in the words of Pasteur, "those sacred dwellings meaningly described as laboratories" through funds provided by, to use the modern idiom, voluntary agencies. To quote the names of a few such laboratories of world-wide repute is to put into perspective the Pasteur Institute of Southern India, this year celebrating the golden jubilee of its foundetion in 1907; Pasteur Institute of Paris, founded in 1890; Institute of Infective Diseases in Berlin (1891) ; Lister Institute of London (1891); Rockefeller Institute for Medical Research of New York (1901) ; Haffkine Institute of Bombay (1896); Pasteur Institute at Kasauli, India (1900). The scientific achievements of the Pasteur Institute of Southern India, so delightfully situated in the Nilgiri Hills at Coonoor, were acclaimed in 1952 by its selection as the venue for the World Health Organization Rabies Conference.

In his foreword to a souvenir volume issued to mark the golden jubilee* the present director, Dr. N. Veer-

* Pasteur Institute of Southern India, Coonoor. Golden Jubilee Souvenir, 1907-1957. Pp. ii $+150+24$ plates. (Coonoor: Pasteur
Institute of Southern India, 1957.) araghavan, pays tribute to the distinguished men who have guided the destinies of the Institute and to the workers to whose unremitting endeavours it owes its position in the scientific world to-day. The directors were : Lieut. Col. J. W. Cornwall, 1907-26 ; Lieut.Col. T. H. Gloster, 1926-28 ; Lieut.-Col. K. R. K. Iyengar, 1928-38 and 1941-46; Major H. W. Mulligan, 1938-41 ; Lieut.-Col. M. L. Ahujo, 1946-47. At its inception, the Institute was a non-governmental organization managed by a committee on which a wide variety of interests were represented. The objectives were to make available effective means of preventing the occurrence of rabies, to spread the knowledge of such means among the public and to undertake research work on rabies or any other disease in so far as funds and the qualifications of the staff permitted. Changes in vaccine for rabies and methods of production over the years are briefly described, and especial reference is made to the painstaking record-keeping, instituted by Cornwall and still maintained, of the history of hundreds of patients bitten by rabid animals, but untreated, considered in parallel with the results of treatment of persons bitten by the same animals ; this continued investigation is considered to be a unique record. In recent years the present director has tested the effect of hyperimmune antirabies serum, as well as a host of drugs claimed to be of therapeutic value in established cases of hydrophobia.

Among many other subjects of research at the Institute have been the entomological studies of Patton about 1920 which culminated in his well. known two-volume text-book; Iyengar's interest in clinical laboratory practice, which led to the creation of a separate department; Mulligan's preoccupation with problems of immunity in malaria and with protozoon parasites generally ; Ahuja's heed for the potency of vaccines and his association with the action of heparin on Russell's viper venom.

The potential for research and expansion available at the Institute to-day is in large measure due to the scientific ability, administrative capacity, sterling character and vision of Col. Cornwall during his twenty years of service as director. To-day the Institute's laboratories co-operate with the World Health Organization in their world-wide studies on rabies, $Q$-fever and international interlaboratory testing of freeze-dried sera from syphilitic and nonsyphilitic sources. Dr. I. G. K. Menon, assistant director, is a member of the World Health Organization expert advisory panel on virus diseases and has instituted new inquiries on the respiratory group of viruses, the intestinal group of viruses and on the recombination and mutations phenomena in influenza viruses.

A section of the souvenir volume describes briefly the scientific contributions by the Institute during fifty years on the following subjects : rabies, influenza, $Q$-fever, cholera, typhoid fever, diphtheria, fusospirochætosis, serology of syphilis, tropical eosinophilia, malaria, leishmaniasis, venoms and entomology. The last section is the Scientific Report of the Institute for the year 1956 and includes an experimental evaluation of recent advances in anti-rabies treatment, an assessment of the value of 5 per cent simple vaccine in human treatment and studies on the cultivation of the rabies virus in vitro.

R. FORD TREDRE 